\title{
FORMAS OBSTRUTIVAS DA NEUROCISTICERCOSE VENTRICULAR
}

\author{
Sylvio de Vergueiro Forjaz* \\ MÁrio Martinez **
}

A aplicação rotineira de conhecimentos cada vez mais amplos sôbre o diagnóstico de cisticercose cerebral vai permitindo que se levante aos poucos o véu que encobre ainda os múltiplos aspectos clínicos dessa moléstia. O quadro que se nos depara nessas circunstâncias é na verdade assustador: em nosso ambiente, onde alta percentagem de consulentes provém do meio rural, a incidência da moléstia no âmbito da especialidade é esmagadora (28\% dos que têm queixa de convulsões). Pela gravidade de suas manifestações, pela facilidade da irfestação em nosso meio desamparado pelo poder público, pela pobreza de recursos terapêuticos, constitui êsse problema, a nosso ver, uma ameaça que se ombreia com a das grandes endemias nacionais.

Não é, entretanto, novo o conhecimento da doença entre nós: Simões Corrêa (1900), Miguel Pereira (1905), Astor de Andrade (1908), Ernani Lopes e Arthur Moses (1911), assinalaram os primeiros casos; Waldemar de Almeida (1915), E. Vampré (1917), Tretiakoff e Pacheco e Silva (1924), Pacheco e Silva (1925), Helion Povoa (1932) estudaram o problema já configuradamente, contribuindo para o progresso do conhecimento de sua patologia e profilaxia. Destacam-se mais recentemente os trabalhos de Monteiro Salles (1934) e vários outros de neurologistas de São Paulo encarando aspectos clínicos e laboratoriais. Muito progresso tem sido realizado nos setores diagnóstico (clínico, radiológico e laboratorial), patológico e terapêutico, mas o conhecimento das formas clínicas (vinculadas à topografia das lesões) tem segredos ainda não desvendados.

A localização do cisticerco no sistema nervoso central não obedece a fatôres conhecidos e, na maior parte dos casos, é múltipla, tal como ocorra com outras moléstias hematogênicas. Decorre dêsse fator, aliás, grande parte das dificuldades diagnósticas. Há, não obstante, localizações mais freqüentes.

1) Localização subaracnóidea (50\% de incidência) - Os cisticercos distribuem-se difusamente na superficie cerebral e cerebelar, ou localizam-se

* Neurocirurgião do Departamento de Cirurgia da Fac. Med. de Ribeirão Prêto, Universidade de São Paulo (Prof. Ruy Ferreira-Santos). ** Assistente do Departamento de Clínica Neurológica da Fac. Med. de Ribeirão Prêto, Universidade de São Paulo (Prof. J. Armbrust Figueiredo). 
nas cisternas basais. A expressão clínica dêstes casos é a meningite aguda ou crônica. Há, de regra, repercussão liquórica com pleocitose moderada (com presença de eosinófilos) e positividade da reação de fixação de complemento para cisticercose. Na fase crônica os exsudatos se organizam com intensa proliferação conjuntiva e glial, formando-se aderências que bloqueiam o trânsito liquórico (hipertensão intracraniana, hidrocefalia). As lesōes tóxico-inflamatórias difusas do parênquima cerebral (principalmente frontais) levam à decadência mental progressiva.

2) Localização parenquimatosa (30\% dos casos) - Faz-se dominantemente na substância cinzenta (córtex e núcleos estriados). São raros os acometimentos do tronco cerebral e cerebelo. Se os parasitos são em pequeno número e isolados, a decorrência sintomática mais comum é a crise convulsiva jacksoniana ou, eventualmente, outros sinais frustros de lesão focal; se a infestação é intensa e difusa, traduz-se em geral pelas crises generalizadas. Agrupamentos volumosos de parasitos funcionam também à maneira das lesões que ocupam espaço, podendo provocar hipertensão intracraniana, além de sinais focais. A repercussão liquórica é, nesta localização, menos freqüente, sobretudo nos casos crônicos, em que o parasito já se calcificou, quando então sua presença é assinalada pelo exame radiográfico simples.

3) Finalmente, podem os cisticercos infestar o sistema ventricular (cêrca de $20 \%$ dos casos), permanecendo livres ou aderentes ao epêndima, isolados ou agrupados, mas sempre em pequeno número. Não é incomum haver apenas uma vesícula isolada nesta ou naquela cavidade. $O$ quadro clínico correspondente pode, não obstante, ser dramático: é que a obstrução das vias liquóricas em suas porções proximais (buracos de Monro, aqueduto de Sylvius, buracos de Magendie e Luschka) acarreta hipertensão intracraniana aguda, com cefaléia, vômitos, distúrbios da consciência e agitação psicomotora.

Nem sempre, porém, o quadro é assim grave e permanente (obstrução total); é mais comum a obstrução parcial que se completa intermitentemente, manifestando-se por cefaléias paroxisticas que remitem espontâneamente. É de supor que nestes casos o cisticerco, nas proximidades dêsses pontos estreitados, funciona à maneira de válvula, ora obstruindo, ora permitindo o fluxo liquórico.

É certo que aderências e o próprio edema inflamatório dos tecidos que delimitam tais orifícios podem causar também obstruções parciais ou totais, estando por vêzes o cisticerco a jusante do ponto obstruído. Com efeito, o cisticerco exerce também ação tóxico-inflamatória à distância, atingindo parênquima, meninges, epêndima (ependimite granulosa) e vasos (endarterite). Os processos obstrutivos, qualquer que seja seu substrato anátomo-patológico (cisticerco, aderências ou edema), podem atingir um ou vários orifícios do sistema ventricular; podem obstruir determinado orifício em certa fase evolutiva da doença e, ulteriormente, sob influência de fatô- 
res vários (pressão liquórica, regressão do processo inflamatório), acometerem outro orifício, determinando modificações do quadro sintomatológico.

Distinguir localizações parasitárias - subaracnóideas, parenquimatosas ou ventriculares - é, na verdade, uma deformação acadêmica da realidade. A regra infelizmente é a associação de localizações, com dominância de danos nesta ou naquela região, de que resultam formas clínicas variadas (convulsivas, meningiticas, pseudotumorais, mentais).

Ainda não existem meios terapêuticos curativos da moléstia pròpriamente dita. Segundo alguns autores, certos medicamentos - extrato etéreo de feto macho, sulfamidas - têm ação sôbre o parasito, levando-o à morte. Mas, mesmo morto, o cisticerco ainda pode agir como corpo estranho irritativo ou obstrutivo. Por outro lado, os processos inflamatórios locais ou à distância que compõem sua patologia e melhoram com o emprêgo das sulfamidas em sua fase aguda, difìcilmente podem se reabsorver quando já organizados em aderências e espessamentos conjuntivais crônicos. Só cabe recurso nestes casos à neurocirurgia que, possibilitando a extirpação de acúmulos parasitários, desbridando aderências ou criando escoamentos artificiais, restabelece o trânsito liquórico represado, resolvendo assim aspectos parciais da doença que podem ser mortais.

Ressalta dessas consideraçōes o enorme interêsse no aperfeiçoamento do estudo das associações sindrômico-topográficas da moléstia. Com efeito, o diagnóstico etiológico já não constitui dificuldade na maior parte dos casos para aquêles que, habituados com a sintomatologia global (incluindo o encontro de nódulos subcutâneos ou musculares), têm recurso ao exame do liqüido cefalorraquidiano, ao exame radiológico simples (que evidencia as imagens características do parasito quando calcificado), aos exames radiológicos contrastados, ao exame eletrencefalográfico. Em certas oportunidades basta a positividade de um elemento subsidiário aliada aos dados do exame clínico-neurológico para a afirmação da etiologia.

Resta-nos agora ordenar os sintomas habituais em síndrome, associando-os à esta ou àquela topografia em têrmos de incidência, para mais eficazmente podermos indicar e usar nossos ainda débeis recursos terapêuticos no alívio dos portadores de cisticercose cerebral.

\section{OBSERVAÇOES}

Caso 1 - M.L.M., sexo feminino, 32 anos. A paciente nos procurou em abril de 1958 com queixa de cefaléia matinal, vômitos e, por vêzes, febre nos 15 dias precedentes. Cêrca de 4 meses antes sofrera também de cefaléia, vômitos e febre, ocasião em que, com apoio em exames subsidiários, fôra feito diagnóstico de febre tifóide (reação de Widal positiva: $\mathrm{O}$ e $\mathrm{H}$ positivos até 1/320). Além disso, o exame de líquiido cefalorraquidiano feito nessa ocasião havia mostrado pleocitose de 566 células por $\mathrm{mm}^{3}$. O exame clínico-neurológico, em abril, mostrou: borramento papilar em A.O.; hiperreflexia profunda generalizada, dominante à esquerda; leves tremores finos no membro superior direito. A reação de Widal mostrou-se ainda positiva, embora com titulos menores (O positivo até $1 / 50$ e H $1 / 100)$. No inicio 
de maio, com sintomas agravados, a paciente foi internada. Exame de liqüido cefalorraquidiano (P.S.O.): hipertensāo (48 cm água), 360 células por $\mathrm{mm}^{3}$ (linfócitos $42 \%$, monócitos $3 \%$, neutrófilos $50 \%$, eosinófilos $5 \%$ ), $48 \mathrm{mg} \%$ de proteínas, 50 $\mathrm{mg} \%$ de glicose, exame bacteriológico negativo. Exame eletrencefalográfico: sofrimento cerebral difuso. Exame oftalmológico: déficit do abducente direito; edema papilar em A.O. com focos hemorrágicos recentes; defeito do pólo superior em A.O. no estudo campimétrico. Carótido-angiografia esquerda: sinais de discreta hidrocefalia. Carótido-angiografia direita: nitida elevação do segmento posterior da artéria cerebral média (M4, M5) e, logo abaixo, uma zona avascular; ligeiro desloca. mento da artéria cerebral anterior direita para o lado esquerdo.

Intervenção cirúrgica - Com diagnóstico provável de abscesso cerebral tifóidico parietal direito fizemos perfuração exploradora com punção cerebral direita, sem resultado. No mesmo ato cirúrgico praticamos outra perfuração occipital esquerda e puncionamos ambos os ventriculos laterais, extraindo liquor $e$ insuflando ar. Amostras separadas de liquor ventricular de um e outro lado foram encaminhadas para exame. Pneumoventriculografias: sistema ventricular algo desviado para á esquerda; ventrículo lateral direito dilatado. Estes resultados reforçaram a suspeita de lesāo expansiva do hemisfério direito, provàvelmente fronto-parietal alta; a paciente foi craniotomizada, mas afora sinais de sofrimento cerebral por hipertensāo e hidrocefalia do ventriculo lateral direito, nada mais de anormal verificamos.
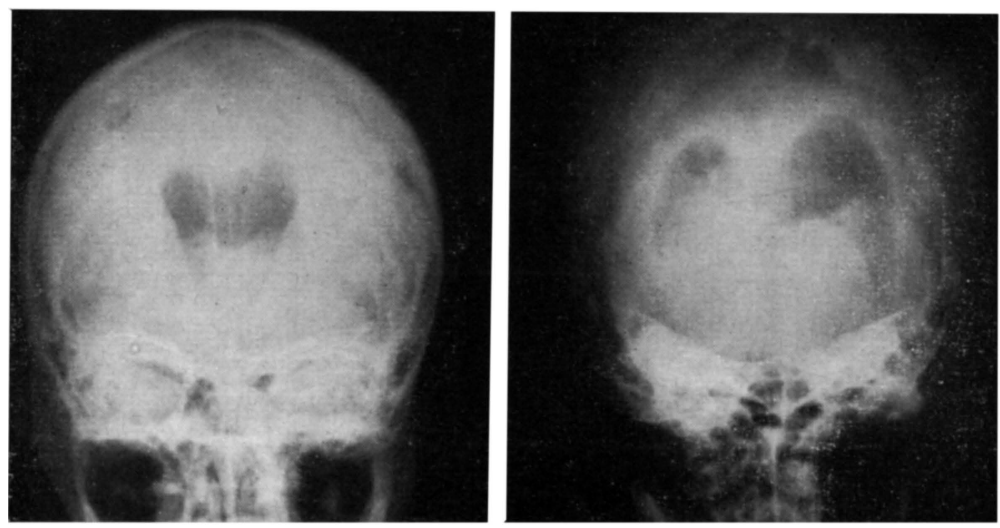

Fig. 1 - Caso 1 (M.L.M.). Pneumoventriculografia: à esquerda posição antero-posterior; à direita, posição obliqua.

Evolução - O pós-operatório foi tormentoso. Após 24 horas recebemos os re. sultados dispares do exame das amostras do líquor dos ventrículos: à esquerda, afora a taxa de proteínas aumentada, os outros elementos estavam dentro da normalidade; á direita, além da pleocitose (180 células por $\mathrm{mm}^{3}$ com eosinófilos), a taxa de proteinas era bem mais alta $(61 \mathrm{mg} \%)$ e a taxa de glicose anormalmente baixa $(31 \mathrm{mg} \%)$. Tais elementos confirmaram a hipótese aventada logo após a operação - ventriculite lateral direita septada - mas a etiologia do processo só foi esclarecida quando recebemos, 6 dias após, os resultados da reação de fixação de complemento para cisticercose praticada nas amostras do líquor ventricular; à esquerda foi negativa e à direita positiva.

A paciente restabeleceu-se bem. Temos acompanhado de perto sua evolução nestes dois anos; o edema papilar regrediu completamente; nunca mais teve cefa- 
léia, vômito ou febre; permaneceu ligeiro déficit campimétrico homolateral esquerdo; 6 meses após o ato cirúrgico a paciente apresentou crise convulsiva com perda da consciência, fenômeno que se repetiu uma vez mais, a despeito da medicação adequada.

Os fatos aqui expostos levam a admitir que esta paciente era portadora de eisticercose ventricular lateral direita bloqueada, bloqueio êste desfeito acidental e involuntàriamente durante a pneumoventriculografia ou com as punçōes ventricillares evacuadoras trans e pós-operatórias.

CASo 2 - M.T. (R.G. 136111), sexo masculino, 18 anos. Paciente com queixa de parestesias e paresia dos membros do lado esquerdo, iniciadas cêrca de 3 meses antes de sua primeira consulta (16-3-1960) no Hospital das Clinicas da Faculdade de Medicina de Ribeirão Prêto; tais sintomas vinham se agravando paulatinamente, quando surgiu cefaléia fronto-parietal direita, acompanhada de vômitos. Internado em hospital de sua cidade a cefaléia e os vômitos cederam. Ulteriormente, recidivando êstes sintomas, foi transferido para a Santa Casa de Ribeirão Prêto onde foi extraído liquor por via suboccipital, tendo resultado positiva a reaçāo de fixação de complemento para cisticercose. Exame clínico-neurológico - Diplopia; paralisia do abducente esquerdo, anisocoria e edema papilar. Ao ser internado, em 6-4-1960, - quadro subjetivo e objetivo de hipertensão intracraniana havia melhorado novamente; hemiparesia à esquerda com moderada dificuldade na linguagem expressiva; a fundoscopia revelou apenas ligeiro borramento papilar. Hemograma: eosinofilia $(35,2 \%)$.

Aguardávamos ainda resultados de outros exames subsidiários quando o paciente entrou em estado de coma na noite de 11 de abril: 12 horas depois o exame dos fundos oculares mostrou acentuado edema papilar com focos hemorrágicos múltiplos; uma punção suboccipital revelou pressão inicial superior a $100 \mathrm{~cm}$ de água, sendo o líquor turvo, com cêrca de 4.000 células por $\mathrm{mm}^{3}$. Carótido-angiografia direita: sinais de lesão expansiva temporal média (fig. 2).
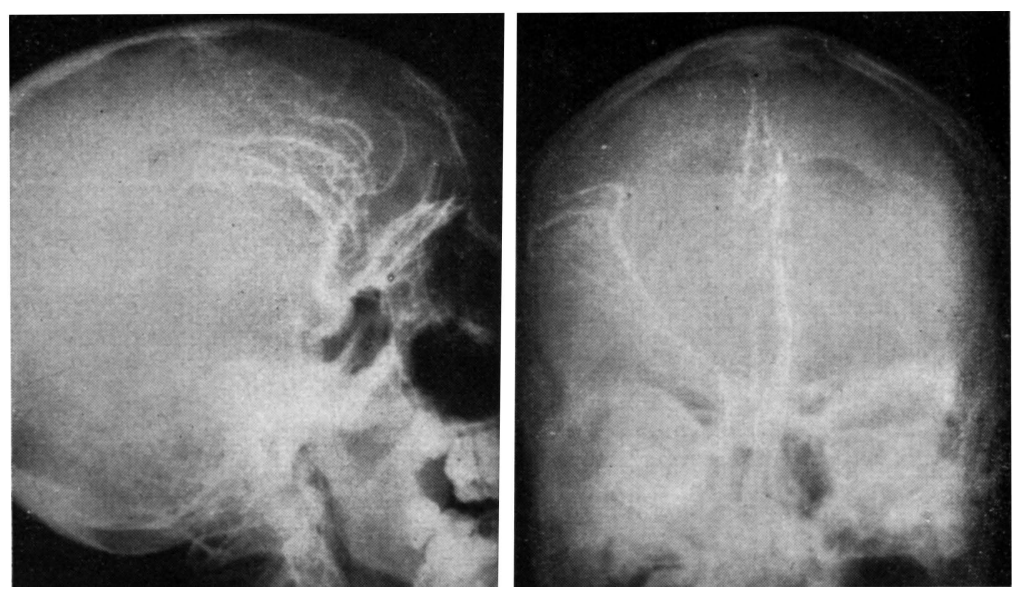

Fig. 2-Caso 2 (M.T.). Carótido-angiografia direita.

Intervenção cirúrgica - Craniotomia têmporo-parietal direita. A enorme tensão intracraniana foi dominada por evacuação de líqüido turvo extraido por punção transdural na região temporal; êsse líqüido revelou-se semelhante em seus aspectos 
fundamentais ao extraido pouco antes da cisterna magna: 4.000 células por $\mathrm{mm}^{3}$ (linfócitos 7,5\%; monocelulares 2,5\%; neutrófilos 70\%; eosinófilos $20 \%$ ), $7 \mathrm{~g} \mathrm{de}$ proteinas totais. Incisado o córtex temporal, entramos no interior de uma cavidade limitada pelas paredes do corno temporal extraordinàriamente dilatado. Em sua luz havia grande acúmulo de exsudatos inflamatórios de côr amarelada de mistura com vesiculas cisticercóticas em sua maior parte degeneradas, todo êste conjunto formando massa fortemente aderente ao epêndima e bloqueando a confluência dos cornos temporal e occipital. Extraída essa massa por tração e aspiração, limpamos a cavidade, restabelecendo o trânsito do líquor. O exame histopatológico do material extraído do ventriculo lateral direito revelou tratar-se de vesículas de cisticercos celulose e fragmentos de tecido conjuntivo frouxo infiltrado por células inflamatórias, exsudato fibrino-leucocitário em organizaçāo.

Evolução - A evolução pós-operatória foi acidentada e o paciente não recuperou a consciência nos 3 meses que precederam o óbito. Entre outros medicamentos recebeu sulfadiazina nos primeiros 15 dias. Sucessivos exames de liquor extraído por punção direta da cavidade ventricular mostraram a regressão do processo inflamatório cisticercótico: em 19-4-1960 o líquor continha apenas 480 células e $95 \mathrm{mg} \%$ de proteinas; em 22-4-1960, 10 células (4\% de eósinófilos) e $80 \mathrm{mg} \%$ de proteínas. Não obstante esta melhora do quadro inflamatório, não houve recuperação do estado de consciência normal, e embora amparado nutritiva e medicamentosamente, o paciente faleceu em caquexia no dia 19 de julho de 1960. Pela necroscopia, verificamos áreas de atrofia nos pedúnculos cerebrais e nos hemisférios; no epêndima do corno temporal direito, áreas pigmentadas atestando o antigo processo inflamatório.

Caso 3 - A.C.S. (R.G. 7407), sexo feminino, 47 anos. A paciente procurou o Serviço de Neurologia da Fac. Med. de Ribeirão Prêto em 12 de abril de 1958, queixando-se de intensa cefaléia iniciada 20 dias antes; 5 dias após início da doença, teve alivio temporário seguido logo de exacerbação violenta, e na semana seguinte, passou a ter vômitos e distúrbios visuais, além de instabilidade do equilibrio. Exame clínico-neurológico - Paciente sonolenta. Não encontramos nódulos subcutâneos. Equilíbrio instável, base de sustentação alargada, tendência à retropulsão. Marcha insegura com incerteza na direção. Motricidade voluntária e tono normais. Reflexos profundos simètricamente exaltados; reflexos cutâneos presentes e simétricos; ausência de reflexos patológicos. Paralisia da elevação do olhar. Pupilas em discreta midriase, ausência do reflexo fotomotor de ambos os lados. Exame do líqüido cefalorraquidiano: punção suboccipital; P.i. 11; P.f. 4; volume retirado $5 \mathrm{ml}$; liquor límpido e incolor; 5,6 células por $\mathrm{mm}^{3} ; 18 \mathrm{mg} \%$ de proteinas totais; 71,5 mg de glicose; por circunstâncias alheias à nossa vontade não foram feitas as reações de desvio de complemento. Radiografia simples do crânio: imagem calcificada pequena, alongada, na porção posterior do $3^{\circ}$ ventrículo. Pneumoventriculografia: sistema ventricular não desviado, moderadamente aumentado de tamanho, sem deformações localizadas; o ar encheu bem $o 3^{\circ}$ ventrículo, mas não passou para o $4^{\circ}$, sendo retido na parte superior do aqueduto de Sylvius, no local onde as radiografias simples haviam mostrado calcificaçāo.

Intervenção cirúrgica - Com diagnóstico de hidrocefalia obstrutiva por bloqueio do aqueduto de Sylvius foj feita craniotomia suboccipital, com abordagem por retalho semicircular bimastóideo. Aberta a dura mater, notamos estreitamento do buraco de Magendie por processo inflamatório crônico; desbridado êste orificio, exploramos o $4^{\circ}$ ventrículo e, a seguir, o aqueduto de Sylvius, cuja iuz, na posição superior, encontramos ocupada por uma formação branco-amarelada, cilíndrica, com $3 \mathrm{~mm}$ de diâmetro e $1 \mathrm{~cm}$ de comprimento, fracamente aderida às paredes đo conduto e que foi extraida fàcilmente por tração. O aspecto macroscópico era de um 
cisticerco, deformado e necrosado. O exame histopatológico revelou material parcialmente necrosado, com numerosas formações arredondadas calcificadas em seu interior. Embora não tivesse conseguido o patologista (Dr. Estêvão Nador) evidenciar estruturas indiscutíveis do parasito com os elementos que ainda permaneciam, optou pela hipótese de cisticerco em degeneração.
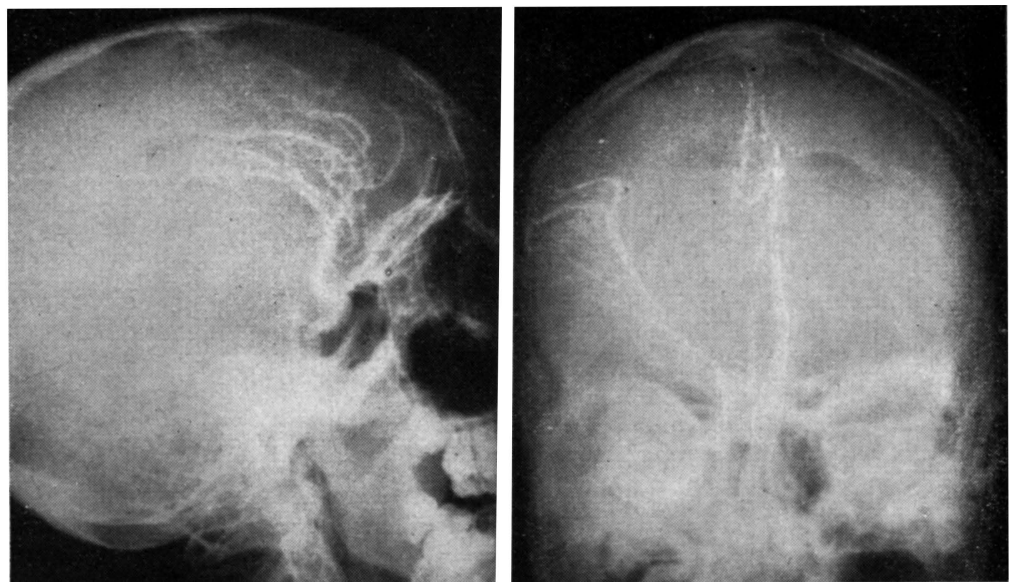

Fig. 3 - Caso 3 (A.G.S.). Pneumoventriculografia: à esquerda, perfil esquerdo; à direita, posiç̃o obliqua posterior.

Evolução - A evolução pós-operatória foi sem incidentes. Desde o primeiro dia, aliviada de sua cefaléia, a paciente readquiriu a motricidade ocular, movimentando livremente o olhar para cima. Os reflexos fotomotores e o diâmetro pupilar também voltaram ao normal.

CASo 4 - I.A.A. (R.G. 7.784), sexo feminino, 29 anos. A paciente foi examinada no Ambulatório do Serviço de Neurologia da Fac. Med. de Ribeirão Prêto em 17 de outubro de 1958, com queixa de distúrbios visuais, vômitos e tonturas, iniciados 3 anos antes, com amauroses passageiras e dificuldade no olhar para cima ou para baixo. Tais sintomas evoluíram com remissões e recidivas, mas progressivamente para pior. Nos últimos meses vinha apresentando sonolência exagerada, leve grau de exoftalmo e tendência à queda para a esquerda quando em posição erecta. Nos antecedentes pessoais e familiares apuramos ter sido infestada por tênia na adolescência. Exame clinico-neurológico - Não apuramos existência de nódulos subcutâneos à inspeção e palpação. Motricidade voluntária e involuntária, tono e coordenação normais. Na marcha, desvios eventuais com perdas de equilíbrio fảcilmente corrigidas. Sensibilidade normal. Anisocoria (pupila direita menor que a esquerda) e perda dos movimentos de verticalidade do olhar; edema papilar bilateral, mais acentuado à esquerda. A paciente foi internada em 30 de outubro de 1958. Exame parasitológico de fezes: cistos de E. nana. Radiografias simples do crânio: normais. Pneumoventriculografia: sistema ventricular moderadamente dilatado, sem desvios; o ar não ultrapassou o aqueduto, mesmo com a cabeça em posição oblíqua posterior; bloqueio do aqueduto de Sylvius em sua porção superior. Exame do liqüido cefalorraquidiano: punção suboccipital; P.i. 17; P.f. 7; liquor límpido e incolor; 4,7 células por $\mathrm{mm}^{3}$ (línfócitos $93 \%$, monócitos $4 \%$, eosinófilos $3 \%$ ); $19 \mathrm{mg} \%$ de proteínas totais; $61 \mathrm{mg} \%$ de glicose; reação de Wassermann negativa; reação de fixação de complemento para cisticercose não reagente. 

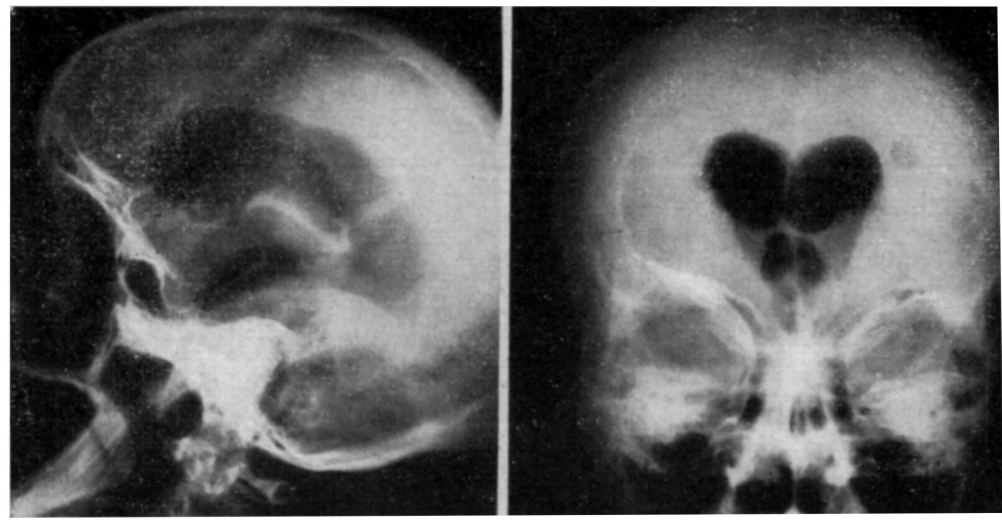

Fig. 4 - Caso \& (I.A.A.). Pneumoventriculografia: à esquerda, perfil direito; à direita, posição occípito-placa.

Intervenção cirúrgica - Craniotomia exploradora da fossa cerebelar, com abordagem por incisão semicircular bimastóidea. Aberta a dura, verificamos espessamento da aracnóide da cisterna magna; incisado o vérmis cerebelar, exploramos a cavidade do $4^{\circ}$ ventrículo, notando que soluto fisiológico introduzido nos ventrículos laterais não fluia pelo aqueduto de Sylvius. Explorando êste conduto por meio de sonda de Nelaton, verificamos estar obstruido em sua extremidade proximal junto ao assoalho da porção posterior do $3^{o}$ ventrículo. Forçando delicadamente a penetração da sonda, tivemos a sensação de vencer resistência; a seguir, notamos o restabelecimento do trânsito liquórico das cavidades superiores para o $4^{\circ}$ ventriculo. Temendo uma reconstituição desta obstrução membranácea, praticamos uma derivação ventrículo-cisternal (Torkildsen).

Evolução - O pós-operatório decorreu muito bem. A paciente queixou-se ainda até a data de alta (23-12-1958) de cefaléia pouco intensa e não acompanhada de vômitos; a paralisia vertical do olhar desapareceu. A paciente foi revista várias vêzes desde sua alta. Cêrca de 5 meses após voltou a apresentar vômitos não relacionados com paroxismos de cefaléia. Reexaminada nessa ocasiāo, verificou-se estar grávida, fato que até então não ocorrera em seus 8 anos de casada. Recentemente (junho de 1960) revimo-la após o parto; paciente sem queixa alguma e com recuperação completa da motricidade ocular.

\section{COMENTARIOS}

Registramos 4 casos de cisticercose cerebral nos quais a infestação atingiu o sistema ventricular excluindo um dos ventriculos laterais (2 casos) ou obstruindo o aqueduto de Sylvius (2 casos).

O bloqueio de um dos buracos de Monro represa o líquor no ventrículo lateral que aumenta enormemente de volume, funcionando à maneira de uma lesão expansiva. Estabelece-se uma síndrome aguda e grave de hipertensão intracraniana, mas os sinais focais são discretos porque a hipertensão se distribui por igual em tôda a superfície interna da cavidade ven- 
tricular lateral. Mas mesmo no interior da cavidade do ventrículo lateral pode haver septação, acumulando-se as massas cisticercóticas e exsudatos inflamatórios na confluência dos cornos temporal e occipital, provocando bloqueio sòmente do corno esfenoidal que, dilatando-se, reproduz clínica e radiològicamente os aspectos dos tumores temporais, tal como ocorreu num dos nossos casos aqui relatados (caso 2).

O bloqueio do aqueduto de Sylvius também acarreta o aparecimento de hipertensão intracraniana, de caráter mais grave do que a provocada pela obstrução de um dos buracos de Monro; nas obstruções do aqueduto de Sylvius são diretamente comprimidas regiões altamente expressivas que formam as paredes do $3 .^{\circ}$ ventrículo, assim como o hipotálamo e o mesencéfalo. Resulta disso o caráter dramático dos sintomas presentes nos casos de bloqueio total do aqueduto de Sylvius.

A anamnese dos pacientes portadores de cisticercose ventricular revela um dado comum: a síndrome de hipertensão intracraniana se manifesta intermitentemente com períodos de acalmia, guardando certa relação com as modificações da posição da cabeça. O exame neurológico, além de edema papilar, pode mostrar sinais focais. Nas obstruçōes do buraco de Monro aparecem sinais piramidais contralaterais; nos bloqueios da parte mais alta do aqueduto, observamos paralisia vertical do olhar (síndrome de Parinaud), com eventual perda dos reflexos fotomotores e midríase.

O exame de líquor revela, em grande percentagem dos casos, hipercitose discreta com eosinófilos e positividade da reação de fixação de complemento para cisticercose. Ãs vêzes tais alteraçōes só estão presentes em amostras de líquor extraídas da cavidade ventricular a montante do bloqueio. Amostras de líquor extraidas diretamente de um e de outro ventrículo lateral podem fornecer dados elucidativos, como ocorreu em um de nossos casos. A disparidade dos achados entre os líquores colhidos dos dois ventrículos laterais permite o esclarecimento diagnóstico definitivo nos casos de bloqueio do buraco de Monro. A comparação dos resultados do exame das amostras de líquor ventricular com os obtidos do líquor suboccipital leva a conclusões idênticas nos casos de obstrução do aqueduto de Sylvius.

O exame radiológico simples do crânio mostra, com freqüência, imagens calcificadas de cisticercos. A pneumoventriculografia é o recurso mais importante para a localização da lesão obstrutiva, seja pelos sinais indiretos (impermeabilidade ao livre trânsito do ar, hidrocéfalo localizado), seja pela melhor contrastação do corpo parasitário encravado neste ou naquele orifício, ou pelas imagens negativas da sombra aérea.

A carótido-angiografia é exame útil, pois revela, pela deformação arterial, a forma globosa do ventrículo lateral (hidrocefalia), mas seus resultados são menos precisos que os da pneumoventriculografia.

O tratamento de tais casos é obviamente cirúrgico. É necessário usar vias de acesso que permitam a abordagem do ponto obstruído para permeabilizá-lo pela extração do cisticerco. A cavidade ventricular excluída, a mon- 
tante, deve também, quando possível, ser inspecionada para a retirada de massas parasitárias e exsudatos organizados porventura existentes. Esta é, em nossa experiência, tarefa difícil, pois tais exsudatos organizados de mistura com vesículas cisticercóticas integras ou parcialmente degeneradas aderem fortemente às paredes ventriculares. São, por outro lado, friáveis, não apresentando resistência para a remoção com pinças, mas não tanto que possam ser extraidas por aspiração. A manobra técnica mais adequada seria a curetagem que, no entanto, comporta riscos de lesão das paredes ventriculares e provoca sangramento abundante.

Quando a obstrução se processa no aqueduto, a via de acesso mais cômoda é pelo $4 .^{\circ}$ ventrículo. Durante o ato cirúrgico, exposto o orifício inferior do aqueduto, a introdução de soluto de Ringer morno nos ventrículos laterais não seguida de seu aparecimento no $4 .^{\circ}$ ventrículo, confirma a existência de bloqueio. Sondando-se o aqueduto com sonda de Nelaton ou mesmo inspecionando-o (quando dilatado), conseguiremos, em certo número de casos, desfazer o bloqueio, extraindo cisticercos, devolvendo-os ao $3 .^{\circ}$ ventrículo ou destruindo as membranas obstrutivas que se tenham formado.

Quando a remoção da rôlha é tècnicamente impossivel, é válido o recurso à derivação ventriculo-cisternal ou ventriculo-ventricular (abertura do septo lúcido). Usamos a primeira (operação de Torkildsen) quando o obstáculo se situa no aqueduto, e a segunda quando se situa no buraco de Monro. Podemos mesmo associá-las supletivamente ao ato cirúrgico bem sucedido, de extirpação do elemento obstrutivo, com o que criamos uma válvula de segurança para futuras reobstruções. Tais operações, simplesmente paliativas quando empregadas em casos de neoplasia obstrutiva dêsses mesmos orifícios, podem dar resultados definitivos em casos de bloqueio cisticercótico.

\section{RESUMO}

A incidência da cisticercose cerebral entre os consulentes orientados para o Ambulatório de Neurologia da Faculdade de Medicina de Ribeirão Prêto é muito alta. Trata-se de moléstia que, pela gravidade de seus sintomas, pela facilidade de infestação e pela precariedade dos recursos terapêticos, representa um probiema individual e social grave nesta região.

Muitos aspectos da moléstia já foram esclarecidos, sendo grande a contribuição de autores brasileiros. Certas feições da moléstia, porém, ainda comportam maiores estudos. É nosso objetivo oferecer uma contribuição ao estudo das formas intraventriculares de neurocisticercose.

Relatamos as observações de 4 pacientes com queixas de hipertensão intracraniana periódica e com achados liquóricos e radiológicos compativeis com a suspeita de cisticercose cerebral. Exames subsidiários (pneumencefalografia ou ventriculografia) mostraram que em dois dêstes pacientes havia bloqueio do aqueduto de Sylvius (casos 3 e 4) e que, nos outros dois, havia 
exclusão de um ventrículo lateral por bloqueio do buraco de Monro (caso 1) e da confluência dos cornos temporal e occipital (caso 2). Nos dois casos em que havia bloqueio na parte alta do aqueduto de Sylvius os pacientes acusavam dificuldade no olhar vertical (síndrome de Parinaud).

O tratamento cirúrgico permitiu desfazer o bloqueio em 3 casos (casos 2, 3 e 4); no caso 1 as punções feitas após a intervenção cirúrgica parecem ter agido benèficamente no sentido de restabelecer o trânsito do líqüido cefalorraquidiano.

Excluindo um paciente (caso 2) que faleceu em caquexia 3 meses após a operação e no qual o exame necroscópico mostrou lesões pregressas imputáveis apenas à hipertensão aguda sem lesões cisticercóticas, os outros casos €voluíram para a cura.

\section{SUMMARY}

\section{Cysticercosis of the nervous system: obstructive forms in ventricular} localization.

In the central and southern parts of Brazil the incidence of cerebral cysticercosis is very high. Infestation is easy, the clinical manifestations are severe and the therapeutic resources are rather ineffectual. Four cases with ventricular obstruction are reported. Two of them presented obstruction in the lateral ventricle and the remaining in the aqueduct of Sylvius. The main complaint was paroxysmal headache in every case, with the objective signs of intracranial hypertension. The cases with localization of the parasite in the aqueduct of Sylvius showed the Parinaud's syndrome.

Diagnosis received confirmation from plain-X-ray and pneumo-encephalographic studies and from the examination of the cerebrospinal fluid. Surgical desobstruction was successful in three cases. The fourth patient died three months after the operation.

\section{REFERENCIAS}

1. ARANA, H.; ASENJO, A. - Ventriculographic diagnosis of cysticercosis of the posterior fossa. J. Neurosurgery, 2:181-190 (maio) 1945. 2. ASSIS, J. L. de; TENUTO, R. A. - Cisticerco racemoso intraventricular: extirpação cirúrgica. Arq. Neuro-Psiquiat. (São Paulo), 6:247-253, 1948. 3. ASSIS, J. L. de; CAMPOS, E. P. de; FRANCA, L. C. M. - Sindrome parkinsoniana na cisticercose cerebral. Estudo anátomo-clínico de um caso. Arq. Neuro-Psiquiat., 13:44-49 (março) 1955. 4. BARINI, O. - Cisticerco macrocístico intramedular: extirpaçāo cirúrgica. Arq. NeuroPsiquiat., 12:264-266 (setembro) 1954. 5. BRONSON, S. R. - Cysticercosis of the brain. Arch. Neurol. a. Psychiat., 45:494-504 (marco) 1941. 6. BROTTO, W. Aspectos neurológicos da cisticercose. Arq. Neuro-Psiquiat., 5:258-294 (setembro) 1947. 7. DICKMAN, G. - Cisticercosis de la fosa craneana posterior. Rev. Neurol. Buenos Aires, 11:160-179 (maio-agôsto) 1946. 8. FORJAZ, S. V.; ARAUJO, R. P. - Ventriculocisternostomia (operação de Torkildsen). Arq. Neuro-Psiquiat., 8:-91- 
96 (março) 1950. 9. LANGE, O. - Sindrome liquórico da cisticercose encéfalomeningea. Rev. de Neurol. e Psiquiat. de São Paulo, 6:35, 1940. 10. LANGE, O. - O líqüido cefalorraqueano na cisticercose do sistema nervoso central. Rev. de Neurol. e Psiquiat. de São Paulo, 2:3-11, 1936. 11. MAGALHAES, A. E. A. - Reação de fixação de complemento para cisticercose no líqüido cefalorraquidiano. Arq. Neuro-Psiquiat., 15:183-189 (setembro) 1957. 12. MONTEIRO SALLES, F. G. - Sôbre o diagnóstico da cisticercose humana. Arq. Inst. Penido Burnier (Campinas), 1:183 (dezembro) 1934. 13. MONTEIRO SALLES, F. G. - Novas considerações sôbre a neurocisticercose. Arq. Inst. Penido Burnier (Campinas), 6:99 (dezembro) 1940. 14. MONTEIRO SALLES, F. G. - Cisticercose Cerebral. Tese de doutoramento, São Paulo, 1934. 15. NIETO, D. - Cysticercosis of the nervous system: diagnosis by means of the spinal fluid complement fixation test. Neurology, 6:725738 (outubro) 1956. 16. PACHECO E SILVA, A. C.; TETRIAKOFF, C. - Contribuição ao estudo da cisticercose cerebral e em particular das lesões tóxicas à distância nesta afecção. Mem. Hosp. Juqueri (São Paulo), 1:55, 1924. 17. PUPO, P. P.; CARDoso, W.; REIS, J. B.; PEREIRA DA SILVA, C. - Sôbre a cisticercose encefálica: estudo clínico, anátomo-patológico, radiológico e do líqüido cefalorraqueano. Arq. Assist. a Psicop. đe São Paulo, 10-11: 3-123, 1945-1946. 18. PUPO, P. P.; MATTOS PIMENTA, A. - Cisticercose do 40 ventriculo: considerações anátomo-clinicas e sôbre a terapêutica cirúrgica. Arq. Neuro-Psiquiat., 7:274-291 (setembro) 1949. 19. REIS, J. B.; DINIZ, H. B.; BEI, A. - Dificuldade no diagnóstico diferencial entre neurolues e cisticercose cerebral. Arq. Neuro-Psiquiat. (São Paulo), 7:156-164 (junho) 1949. 20. REIS, J. B. - Contribuição do laboratório para o diagnóstico da cisticercose encefálica. Resumo em Rev. Paul. Med., 43:164-165, 1953. 21. RUBINO, A. - Cisti idatidea del 49 ventriculo, con leptomeningite opto-chiasmatica. Riv. Patol. Nerv. Mentale, 53:249, 1939. 22. SILvA, J. A. C. (Jr.) Cisticercose cerebral: resultados obtidos com tratamento sulfamidico. Arq. NeuroPsiquiat., 9:43-47 (março) 1951. 23. SILVEIRA, A.; ROBORTELLA, M.; MAFFEI, W. E. - Quadro clínico do lobo orbitário com crises cerebelares: cisticercose racemosa. Arq. Neuro-Psiquiat., 18:152-165 (junho) 1960, 24. SPINA-FRANCA, A. Cisticercose do sistema nervoso central. Rev. Paul. Med. (São Paulo), 48:59-70, 1956. 25. STEPIEN, L.; CHOROBSKI, J. - Cysticercosis cerebri and its operative treatment. Arch. Neurol, a. Psychiat., 61:499-527 (maio) 1949. 26. SYLVA, L. -Diagnóstico em vida da cisticercose cerebral. Arq. Assist. Psicopt. São Paulo, 7: $232,1942$.

Departamento de Cirurgia, Faculdade de Medicina - Ribeirão Prêto, Estado de São Paulo. 